\title{
Cloud Centric loT Framework for Supply Chain Management
}

\author{
Prashant Satpute \\ Department of Computer Engineering \\ Dr, D.Y.Patil SOET, \\ Lohegaon, Pune
}

\author{
Aarti Mohanpukar \\ HOD, Department of Computer Engineering \\ Dr, D.Y.Patil SOET, \\ Lohegaon, Pune
}

\begin{abstract}
Cloud computing is aimed at providing IT as a service to the cloud users on-demand basis with greater flexibility, scalability, reliability and availability with utility computing model. This new ideal model of computing has a tremendous potential in it to be utilized as a part of the agriculture furthermore in rural improvement viewpoint in creating nations like India. There are some crucial issues to be solved to successfully deploy cloud computing for these social purposes. With the development of Cloud Computing and its consequent popularity, the service providers are coming up with extremely exposition and reasonable answers for the end clients. This innovation is anticipated to bring progressive changes to the agriculture division. Supply chains are progressively virtualized with the goal of building a synchronizing supply with interest aggressive framework, synchronizing supply with demand competitive infrastructure, creating net value and measuring performance. This paper concentrates on how Cloud Computing idea improves virtualization of supply chains in agribusiness segment. Farmers can get most advance grade cultivating and virtualization of supply chains systems, additionally track and check the entire methodology from production, distribution to consumption.
\end{abstract}

\section{General Term \\ Cloud of Things}

\section{Keywords}

Cloud Computing, Supply Chain Management, Internet of Things, Virtual Commerce, Agriculture.

\section{INTRODUCTION}

Agriculture sector is the broadest economic division and assumes a critical part in the general economic development of India. Today, India positions second worldwide in Agriculture production. 13.7\% of the GDP (Gross Domestic Product) in 2013 is based upon Agriculture and allied sectors like forestry and fisheries for $13.7 \%$ of the GDP (Gross Domestic Product) in 2013. India is the world's biggest vote based system with 1.2 billion populations. Notwithstanding with its present position, the sector needs to look forward with target of advancing new things and to stay leading the pack. While reducing food supply chain losses, the focus has been given on improving production. This advantages issue of food wastage combating hunger and improving food security. It is hard to realize that the amount of food is lost and wasted in India today because of absence of proper infrastructure. However, a 2011 report by a UN body, gives data about wastage in products of the soil as high as $45 \%$ of produce (post-harvest to distribution) in India.
In India, significant part of the agro supply chain system framework is either in people in general area, or unequivocally related to it. The Indian government chooses price of produce after analyzing the costs of growing a specific harvest at Minimum Support Prices (MSP"s), chose by the Commission at Agricultural Costs and Costs The part of the purchaser, putting away the acquired produce played by, the 7500+ Agricultural Procurement and Marketing Committee (APMC) "mandis" give a commercial center for the exchange and the Food Corporation of India (FCI). This gets distributed through the Public Distribution System (PDS) shops and achieves the purchaser. The maker is reliant on the traditional private channels to market her produce, for nonMSP crops.

An application of Information Communication Technology (ICT) will cater all such data needs of an Indian farmer at an extremely reasonable and affordable expense. That most recent and most promising region of ICT is Cloud Computing. It empowers the clients to make utilization of various services and tools with pay-per use basis without the need to know the physical location. Cloud computing gives more accessible, dependable and upgraded administrations to their customers thus. Cloud comprises of physical machines in the server farms of cloud suppliers. The cloud gives administrations like Platform as a Service, Software as a Service or Infrastructure as a Service. Cloud goes about as the single purpose of access for serving all clients and web is the medium for getting to these administrations. Taking about the potential benefit of cloud computing we can list out its part in agricultural advancement in India. Utilizing the applications of cloud the farmers have nothing to stress over hardware and software investment and also the specialized learning needed to learn them. The agriculturists will send the appeal for the particular cloud administration utilizing a user friendly device, and the cloud administration supplier will examine and handle the request, lastly the results will be passed once more to the customer. They can get most progressive cultivating and proliferation procedures, pest control information, and can likewise track and check the entire procedure from generation, distribution to utilization. They can likewise power the systematic methods in information collection, supply chain logistics, market forecasting and business decision-making.

In such virtual supply chains, arranging, organization and coordination are focused around virtual representations of physical products and resources, enabled by new information and communication technologies. The actors in charge of arranging, organization and coordination are not necessarily the ones handling and observing these physical objects. They can be at total different locations. [1] 
The most recent and most promising area of ICT is Cloud Computing. It empowers the clients to make utilization of decentralization or decoupling of physical streams from centralized planning, orchestration, and coordination taking place in other locations and by other partners. The Internet of Things (IoT) standard has point of interest of ubiquitous interconnection of billions of embedded devices that can be uniquely identified, localized, and communicated [2].IoT architectures are either Internet driven or object driven. Scalability and cost efficiency of IoT services can be accomplished by the integration of cloud-computing into the IoT architecture, i.e., cloud-centric IoT [3][4][5]. Applications that can be enhanced by the coordination of Iot into cloud computing are many, for example, healthcare [6], smart homes [7], smart cities [8], and future transportation systems [9]. In this manner, Supply Chain administration can be efficiently addressed by taking advantage of cloud and IoT integration.

This paper is structured as follows. In section II, related work is presented. Section III gives architecture details which identifies how cloud centric IoT framework utilised for supply chain management. Section IV gives implementation details and concludes with section $\mathrm{V}$.

\section{RELATED WORK}

All Supply chain management (SCM) is the strategic, systematic coordination of the traditional business functions and the tactics across business functions. The purposes of the supply chain are to improve the long term performance of different companies. [10] The requirements of the SCM are sensing objects, the proposed deployment, development, and management of the IoT applications over the cloud, namely, cloud-centric IoT framework. In a cloud-centric IoT framework [4], sensors provide their sensed data to a storage cloud as a service, which then undergoes data analytic and data mining tools for information retrieval and knowledge discovery. Built-in sensors in mobile devices can leverage the performance of IoT applications in terms of energy and communication overhead savings [11], [12]. Therefore, It has a benefit of strong candidate for front-end access to the cloudcentric IoT, where mobile devices provide their sensed data based on the pay-as-you-go fashion [13].

\section{METHODOLOGY}

In this proposed work, The SCM is primarily concerned with coordination of flow dependencies; the business process output of one actor is the input of another actor"s processes. The main component supply chain business processes are orders, products, and demand and supply information. Besides these independent dependencies, there are some key dependencies are related to the usage of shared resources [1]. In proposed framework for SCM, the control and Coordination of supply chain process is based on sensed objects instead direct observation of physical objects. This Cloud based IoT Framework removes fundamental constraints concerning place, time and human observations.

Cloud centric IoT Architecture has following layers in proposed framework,

- Object Management

- Cloud Computing Platform

- Information as a Service

- Smart Phone User

\section{A. Object Management}

Objects are digital representation of information that communicated and processed via Internet, Objects have central role in SCM, and In SCM objects are information exchanged between different partners from primary production to the market. These objects submits sensing task request to the cloud platform and receives sensing data of corresponding task.

\section{B. Cloud Computing Platform}

Maintains a user database where objects, sensing tasks and associated events are stored. This middleware enables a seamless exchange of object information between different supply chain participants. Cloud centric IoT framework processes functionalities for service management and service composition. The data exchange and information integration is done by this platform.

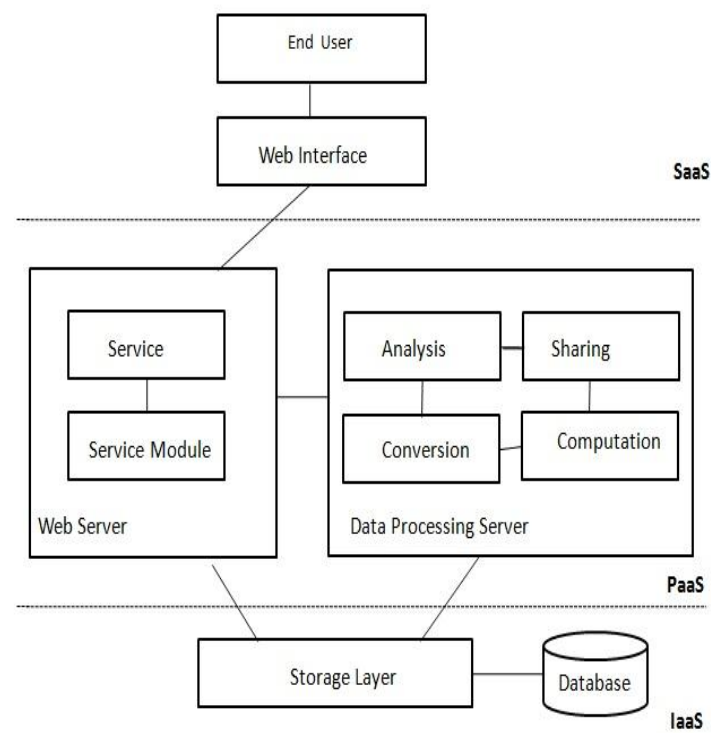

Fig. 1 System Architecture

\section{Information as a Service}

This layer considered as data publisher layer in this cloud centric IoT framework for Supply Chain Management. The specific service for different supply chain user based on the object information made accessible by using web interface application.

\section{Smart Phone User}

The farmers will send the request for the specific cloud service using a user friendly device such as smart phone users, and the cloud service provider will analyse and handle the request dynamically. A user who to publish his sensed object data on object management layer must use the benefit of smart phones by installing application on his smart phone.

System Architecture performs following operations,

$>$ Users of these systems submit the request to cloud platform.

$>$ Cloud computing platform answers the users who corresponding location.

$>$ Updating of user database is done by this computing platform. Users publish their sensed object information. 
$>\quad$ The Cloud performs computing operation upon receiving sensed object. And it sends user-task matching according to physical location.

> The data processing server does operations of analysis, sharing, conversion on sensed object sends the sensed data of submitted task to end user information.

\section{E. Mathematical Notations}

Cloud computing data center is weighted undirected graph of the form,

$$
\mathrm{S}=(\mathrm{D}, \mathrm{C}, \mathrm{T}, \mathrm{U}, \mathrm{O})
$$

Where,

$\mathrm{D}$ is number of nodes in the system, $\mathrm{C}$ represents computing node which performs all dynamic activities, $\mathrm{T}$ be the service provided to the user, $\mathrm{U}$ be the participants of SCM, O is the object information related to particular location. Let demand of $\mathrm{D}$ resources during the interval 0 , $\mathrm{t}$ be the time,

$$
\mathrm{t}=\mathrm{Oi}<\mathrm{Ti}<\mathrm{T}
$$

Value of set $\mathrm{D}, \mathrm{V}(\mathrm{D})$ denotes total number of nodes who submits the sensed object information request. Tw is the list of task by the computing node in set $\mathrm{S}$, as

$$
V_{D}=\sum_{t=T w} V_{T}
$$

Cloud optimization is subject to two categories constraints, first is capacity constraints which defines resource usage. Another is QoS constraints which relate the system performance.

\section{IMPLEMENTATION DETAILS}

We assume that the built in sensors of smart phones provide highly accurate readings at $0.97-.98$ [20]. It is assumed that we evaluate the SCM framework in particular region with preinstalled application on their smartphones. Cloud Stack open source cloud computing tool used to manage distributed data center infrastructure used in proposed work. The task of managing virtual services is done by this open source platform with high security. On client side a simple application is designed to deal with problem. By using such system, Farmers are nothing to worry about hardware and software installment and technical knowledge to learn them. The farmers will send the request for specific service using user friendly device, the cloud service provider handles the request dynamically, and finally results will be passed back to the clients.

\section{CONCLUSION}

Modern technology is rapidly altering and enhancing all aspects of our lives. The communication sector has been improving continuously. The Cloud computing is a game changing phase of IT that promises several benefits but the challenges too need to be considered when planning for Cloud adoption in agricultural sector. Agriculture has traditionally been maintained by families and communities where passing on and sharing of knowledge is regarded very important. The accumulation and sharing of knowledge has resulted in better productivity and efficiency. Agriculture is the embodiment of large amount of ancient knowledge. If the leverage effects of IT can be widely developed, then we able to bring about a further leap in agriculture. Research also continues to analyse
Cloud computing implementation that provides less or no expenditure, On-Demand, Efficient Agricultural Knowledge Management. The cloud can offer a centralized knowledge bank which plays a big role in agriculture sector.

\section{ACKNOWLEDGMENT}

We would like to thank to researchers for making their resources available and teachers for guidance, support, suggestions and encouragement.

\section{REFERENCES}

[1] C.N. Verdouw, A.J.M. Beulens, J.G.A.J. van der Vorst, "Virtualisation of floricultural supply chains: A review from an Internet of Things perspective", Computers and Electronics in Agriculture 99 ,Elsevier (2013) 160-175

[2] C. Aggarwal, N. Ashish, and A. Sheth, "The Internet of Things: A survey from the data-centric perspective," in Managing and Mining Sensor Data, C. C. Aggarwal, Ed New York, NY, USA: Springer, 2013, pp. 383-428

[3] Burak Kantarci, Hussein T. Mouftah, " Trustworthy Sensing for Public Safety in Cloud-Centric Internet of Things", IEEE INTERNET OF THINGS JOURNAL, VOL. 1, NO. 4, AUGUST 2014

[4] Burak Kantarci, Senior Member, IEEE, and Hussein T. Mouftah, Fellow, IEEE, Trustworthy Sensing for Public Safety in Cloud-Centric Internet of Things, IEEE INTERNET OF THINGS JOURNAL, VOL. 1, NO. 4 AUGUST 2014

[5] A. E. Al-Fagih, F. M. Al-Turjman, W. M. Alsalih, and H. S. Hassanein, "A priced public sensing framework for heterogeneous IoT archi- tectures," IEEE Trans. Emerging Topics Comput., vol. 1, no. 1, pp. 133-147, Jun. 2013

[6] J. Gubbi, R. Buyya, S. Marusic, and M. Palaniswami, "Internet of Things (IoT): A vision, Architectural elements, and future directions," Future Generat. Comput. Syst., vol. 29, no. 7, pp. 1645-1660, 2013.

[7] C. Doukas and I. Maglogiannis, "Bringing IoT and cloud computing towards pervasive healthcare," in Proc. 6th Int. Conf. Innov. Mobile Internet Services Ubiquitous Comput. (IMIS), Jul. 2012, pp. 922-926.

[8] S.-Y. Chen, C.-F. Lai, Y.-M. Huang, and Y.-L. Jeng, "Intelligent homeappliance recognition over IoT cloud network," in Proc. 9th Int. Wireless Commun. Mobile Comput. Conf., Jul. 2013, pp. 639-643.

[9] G. Suciu et al., "Smart cities built on resilient cloud computing and secure Internet of Things," in Proc. 19th Int. Conf. Control Syst. Comput. Sci. (CSCS), May 2013, pp. 513-518

[10] X. Yu, F. Sun, and X. Cheng, "Intelligent urban traffic management system based on cloud computing and Internet of Things," in Proc. Int. Conf. Comput. Sci. Service Syst. (CSSS), Aug. 2012, pp. 2169-2172.

[11] Mentzer, John T., William DeWitt, James S. Keebler, Soonhoong Min, Nancy W. Nix, Carlo D. Smith, \& Zach G. Zacharia (2001): "Defining Supply Chain Management", Journal of Business Logistics, Vol. 22, No. 2, pp. 1-25.

[12] C. Perera, P. Jayaraman, A. Zaslavsky, P. Christen, and D. Georgakopoulos, "Dynamic configuration of sensors using mobile sensor hub in Internet of Things paradigm," 
in Proc. IEEE Int. Conf. Intell. Sensors, Sensor Netw. Inf. Process., Apr. 2013, pp. 473-478.

[13] A. E. Al-Fagih, F. M. Al-Turjman, W. M. Alsalih, and H. S. Hassanein, "A priced public sensing framework for heterogeneous IoT architectures," IEEE Trans. Emerging Topics Comput., vol. 1, no. 1, pp. 133-147, Jun. 2013.

[14] X. Sheng, X. Xiao, J. Tang, and G. Xue, "Sensing as a service: A cloud computing system for mobile phone sensing," in Proc. IEEE Sensors, Oct. 2012, pp. 1-4.

[15] Joseph Bradley, James Macaulay, Andy Noronha, Hiten Sethi "Impact of Cloud on IT Consumption Models ", Survey Report, Produced in partnership with Intel.

[16] Kerry Taylor, Colin Griffith, David Lamb, Greg Falzon, and Mark Trotter, "Farming the Web of Things", IEEE INTELLIGENT SYSTEMS Published by the IEEE Computer Society
[17] Anupriya Tuli, Nitasha Hasteer, Megha Sharma, Abhay Bansal, "Framework to Leverage Cloud for the Modernization of the Indian Agriculture System “, IEEE 2014

[18] Mahyar Amini , Nazli Sadat Safavi , Shamila Sohaei, Seyyed Morteza Noorbakhsh , "Agricultural Development In IRAN Base On Cloud Computing Theory", International Journal of Engineering Research \& Technology (IJERT), June - 2013

[19] Nir Kshetri, "Cloud Computing in India", Published by the IEEE Computer Society, 2012

[20] Ishita Verma, "Agri-logistics in India Challenges and Emerging Solutions - Unitus Capital"

[21] Y. He and Y. Li, "Physical activity recognition utilizing the built-in kinematic sensors of a smartphone," Int. J Distrib. Sensor Netw., vol .2013, 2013, doi:10.1155/2013/481580. 